\title{
Combined Generalized Hubbert-Bass Model Approach to Include Disruptions When Predicting Future Oil Production
}

\section{Steve H. Mohr, Geoffrey M. Evans}

School of Engineering, The University of Newcastle, Callaghan, NSW, Australia.

Email: Steve.Mohr@uon.edu.au

Received August $30^{\text {th }}$, 2010; revised September $20^{\text {th }}$, 2010; accepted September $25^{\text {th }}, 2010$.

\begin{abstract}
In a previous study [1] the authors had developed a methodology for predicting global oil production. Briefly, the model accounted for disruptions in production by utilising a series of Hubbert curves in combination with a polynomial smoothing function. Whilst the model was able to produce predictions for future oil production, the methodology was complex in its implementation and not easily applied to future disruptions. In this study a Generalized Bass model approach is incorporated with the Hubbert linearization technique that overcomes these limitations and is consistent with our previous predictions.
\end{abstract}

Keywords: Generalized Bass Model, Hubbert Curve, Oil Production

\section{Introduction}

It has been reported that world oil production will peak between 1996 and 2048 [2-16]. Typically, the modelling analysis is based on the Hubbert curve, which is defined as:

$$
\frac{d Q(t)}{d t}=r Q(t)\left(1-\frac{Q(t)}{Q_{T}}\right)
$$

where $Q(t)$ is cumulative production, $Q_{T}$ is the ultimately recoverable resource (URR), defined as the sum of all historical and future production, $r$ is a rate constant, and $t$ is time. Equation (1) can be integrated to obtain:

$$
Q(t)=\frac{Q_{T}}{\exp \left(-r\left(t-t_{p}\right)\right)+1},
$$

where $t_{p}$ is the year when annual production is expected to peak. Differentiation of Equation (2) gives:

$$
\frac{d Q(t)}{d t}=r Q_{T}\left[\frac{\exp \left(-r\left(t-t_{p}\right)\right)}{\left[1+\exp \left(-r\left(t-t_{p}\right)\right)\right]^{2}}\right] .
$$

The Hubbert curve, as described by Equation (3), has been widely used for modelling oil production as the constants $r, Q_{T}$ and $t_{p}$ can be readily quantified by apply- ing Hubbert linearization techniques to historical production data. The disadvantage with the Hubbert approach, however, is that while it is possible to include disruptions the methodology for doing so is very tedious [1].

A recent alternative to the Hubbert curve is the Generalized Bass model, and is defined as [15]:

$$
\frac{d \hat{Q}(t)}{d t}=\hat{Q}_{T}\left(r_{1}+r_{2} \frac{\hat{Q}(t)}{\hat{Q}_{T}}\right)\left(1-\frac{\hat{Q}(t)}{\hat{Q}_{T}}\right) x(\tau),
$$

where $r_{1}$ and $r_{2}$ are rate constants, $\hat{Q}_{T}$ is the URR, and $x(t)$ is an intervention function used to insert a disruption. Equation (4) has the general solution:

$$
\hat{Q}(t)=r_{1} \hat{Q}_{T}\left[\frac{1-\exp \left(-\left(r_{1}+r_{2}\right) \int_{0}^{t} x(\tau) d \tau\right)}{r_{1}+r_{2} \exp \left(-\left(r_{1}+r_{2}\right) \int_{0}^{t} x(\tau) d \tau\right)}\right],
$$

which can be differentiated to obtain:

$$
\frac{d \hat{Q}(t)}{d t}=r_{1} \hat{Q}_{T} x(\tau)\left[\frac{\left(r_{1}+r_{2}\right)^{2} \exp \left(-\left(r_{1}+r_{2}\right) \int_{0}^{t} x(\tau) d \tau\right)}{\left[r_{1}+r_{2} \exp \left(-\left(r_{1}+r_{2}\right) \int_{0}^{t} x(\tau) d \tau\right)\right]^{2}}\right] .
$$

Guseo et al. [15] modelled the intervention function as a summation of disruptions, $i \in\{1, \ldots, n\}$ : 


$$
x(\tau)=1+f_{1}(\tau)+f_{2}(\tau)+\ldots+f_{n}(\tau),
$$

with each disruption having an exponential form, i.e.:

$$
f_{i}(t)=c_{i} \exp \left(b_{i}\left(t-t_{d i}\right)\right) H\left(t-t_{d i}\right),
$$

where $t_{d i}, b_{i}$ and $c_{i}$ are the commencing year, rate constant and constant of the $i$-th disruption, respectively. $H\left(t-t_{d i}\right)$ is the unit step function, commencing in year $t_{d i}$, and is defined as:

$$
H\left(t-t_{d i}\right)= \begin{cases}0 & , t-t_{d i}<0 \\ 0.5 & , t-t_{d i}=0 \\ 1 & , t-t_{d i}>0\end{cases}
$$

The advantage of the Generalized Bass model approach is that disruptions can be readily accommodated by the intervention function $x(t)$. However, unlike the Hubbert approach, the generalized Bass model constants $r_{1}$ and $r_{2}$ are not readily quantified from existing production statistics.

\section{Results and Discussion}

World oil production has been modelled using the Generalized Bass model (GBM), given by Equation (6), with the inclusion of the following three disruptions:

1) 1973, OPEC crisis,

2) 1979, OPEC crisis, and

3) 1990, collapse of the former Soviet Union (FSU).

In applying the GBM, the functions $f_{i}(t)$ have been modified $^{1}$ so that they linearly decrease for $t_{r}$ years before exponentially decaying back to zero. Mathematically, this is given by:

$$
f_{i}(t)= \begin{cases}0 & , t<t_{d i} \\ c_{i}\left(t-t_{d i}\right) / t_{r i} & , t_{d i} \leq t<t_{d i}+t_{r i} \\ c_{i} \exp \left(b_{i}\left(t-t_{d i}-t_{r i}\right)\right) & , t_{d i}+t_{r i} \leq t\end{cases}
$$

Numerical values for the constants, $c, b, t_{d}$, and $t_{r}$ were obtained by fitting Equation (10) to the historical data. The actual value of these constants depends on the chosen URR value, as indicated in Table 1.

The comparison between the GBM (this study) and the corresponding Hubbert-based model (MHM) by Mohr and Evans [1] for the two URR scenarios is given in Figure 1. It can be seen that in both cases the GBM and MHM curves are similar, Quantitatively, for a URR of $2234 \mathrm{~Gb}$ (Figure 1(a)), the GBM projects a peak in global oil production of $29 \mathrm{~Gb} / \mathrm{y}$ to occur in 2009; with 90 percent depletion by 2047. The corresponding peak in

\footnotetext{
${ }^{1}$ The original exponential function, Equation $(8,9)$ assumed by Guseo et al. [15] had a positive rate constant, $b$, which meant that the disruption, $f$, increased with time. In reality, any disruption must eventually dissipate over time.
}

Table 1. Fitted values for constants used in Equation (10).

\begin{tabular}{ccccccc}
\hline Constant & \multicolumn{2}{c}{$\begin{array}{c}1973 \text { OPEC } \\
\text { crisis }\end{array}$} & \multicolumn{2}{c}{$\begin{array}{c}\text { 1979 OPEC } \\
\text { crisis }\end{array}$} & \multicolumn{2}{c}{$\begin{array}{c}\text { 1990 collapse } \\
\text { FSU }\end{array}$} \\
\hline$\widehat{Q}_{T}(\mathrm{~Gb})$ & 2234 & 2734 & 2234 & 2734 & 2234 & 2734 \\
$C_{1}(-)$ & -0.100 & -0.130 & -0.240 & -0.270 & -0.040 & -0.065 \\
$b_{1}\left(\mathrm{y}^{-1}\right)$ & -0.015 & -0.020 & -0.001 & -0.001 & -0.060 & -0.001 \\
$t_{d 1}(\mathrm{y})$ & 1974 & 1974 & 1979 & 1979 & 1990 & 1990 \\
$t_{r 1}(\mathrm{y})$ & 1 & 1 & 4 & 4 & 1 & 1 \\
\hline
\end{tabular}

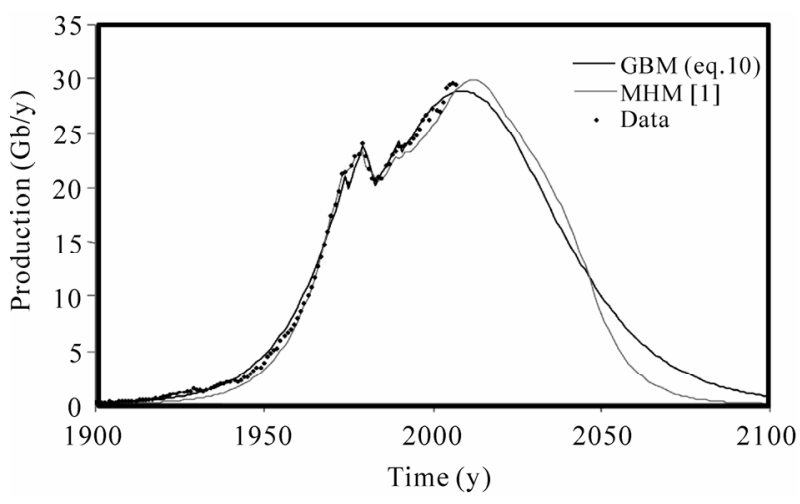

(a)

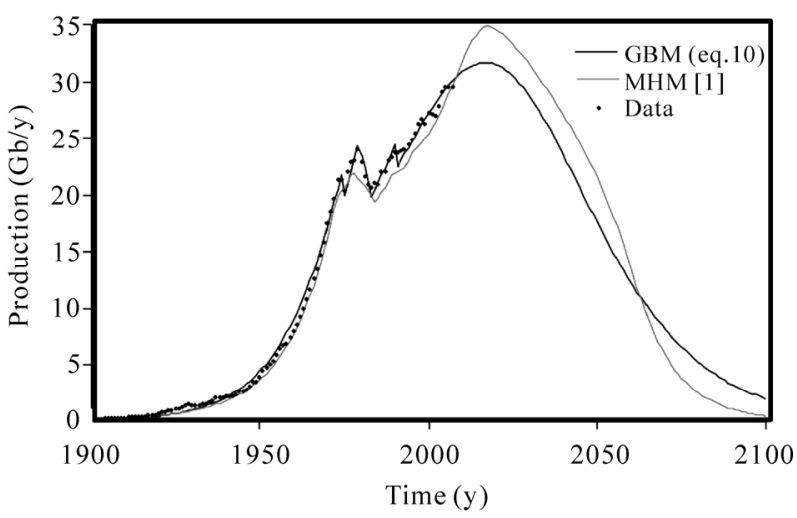

(b)

Figure 1. GBM and MHM [1] Comparison. (a) URR = 2234 Gb; (b) URR = 2734 Gb.

production for the MHM is $30 \mathrm{~Gb} / \mathrm{y}$ at 2012; with $90 \%$ depletion by 2045. Similarly, for a URR of $2734 \mathrm{~Gb}$ (Figure 1(b)), the GBM shifted the oil production peak to 2017 at $32 \mathrm{~Gb} / \mathrm{y}$, with 90 percent depletion taking place by 2060. By comparison, for the MHM the predicted peak year was 2024 at $34 \mathrm{~Gb} / \mathrm{y}$, with 90 percent depletion occurring in 2053.

In producing the Generalized Bass Model predictions, values for the rate constants $r_{1}$ and $r_{2}$ needed to be determined. Usually, these two terms are varied arbitrarily 
until the curve matches the historical data, or fitted using least squares or similar techniques. An alternative approach was applied. Firstly, the following expressions were developed:

$$
\begin{aligned}
& r_{1}=r \frac{\exp \left(-r t_{p}\right)}{\exp \left(-r t_{p}\right)+1} \\
& r_{2}=r \frac{1}{\exp \left(-r t_{p}\right)+1}
\end{aligned}
$$

which relates $r_{1}$ and $r_{2}$ to the constants $r$ and $t_{p}$, used in the Hubbert analysis. By doing this, the Hubbert Linearization technique can then be applied to the production data, from 1857 up to the year of the first disruption in 1973, to obtain $r$ and $t_{p}$, and ultimately $r_{1}$ and $r_{2}$. From the historical data, $r$ was determined to be $0.075 \mathrm{y}^{-1}$, with $t_{p}$ values of 141 and 144 years, for URRs of 2234 and $2274 \mathrm{~Gb}$, respectively. Substitution of these values into Equations (11) and (12) resulted in an $r_{2}$ value $^{2}$ of 0.075 $\mathrm{y}^{-1}$, and corresponding $r_{1}$ values of 1.916 and $1.530 \times 10^{-6}$ $\mathrm{y}^{-1}$, URRs of 2234 and $2274 \mathrm{~Gb}$, respectively.

The approach described above has two advantages. Firstly, the use of Hubbert analysis, and in particular the linearization methodology, is adopted to obtain constants $r_{1}$ and $r_{2}$ for the Generalised Bass model. Secondly, the Generalized Bass Model approach is applied, which is readily able to include disruptions. The use of Hubbert analysis, however, does rely on the validity of Equations (11) and (12) and the justification for the use of these equations is given in appendix 1 .

\section{Conclusions}

The study has demonstrated that a Generalized Bass Model with Hubbert analysis can be used to include disruptions in oil production. The predictions are consistent with previous work based on a more tedious approach of using a combination of Hubbert curves and smoothing functions. The advantage of the new approach is that Hubbert Linearization can be readily applied to obtain values for Generalised Bass model constants based on historical data.

\section{REFERENCES}

[1] S. H. Mohr and G. M. Evans, "Mathematical Model Forecasts Year Conventional Oil Will Peak," Oil and Gas Journal, Vol. 105, No. 17, 2007, pp. 45-50.

[2] A. S. Al-Jarri and R. A. Startzman, "Worldwide Petroleum-Liquid Supply and Demand,” Journal of Petroleum Technology, Vol. 49, No. 12, 1997, pp. 1329-1338.

$\overline{{ }^{2} r_{2} \text { was only approximately } 0.075 \text {, in reality it was found to be } 0.075-r_{1}}$, however $r_{1}$ is very small.
[3] D. L. Greene, J. L. Hopson and J. Li, "Have We Run out of Oil Yet? Oil Peaking Analysis from an Optimist'S Perspective,” Energy Policy, Vol. 34, 2006, pp. 515-531.

[4] S. H. Mohr, "Projection of World Fossil Fuel Production with Supply and Demand Interactions," Ph.D. dissertation, the University of Newcastle, Australia, 2010. http://dl. dropbox.com/u/8223301/Steve\%20Mohr\%20Thesis.pdf

[5] I. S. Nashawi, A. Malallah and M. Al-Bisharah, "Forecasting World Crude Oil Production Using Multicycle Hubbert Model,” Energy and Fuels, Vol. 24, No. 3, 2010, pp. 1788-1800.

[6] K. S. Deffeyes, "World's Oil Production Peak Reckoned in Near Future," Oil and Gas Journal, Vol. 100, No. 46, 2002, pp. 46-48.

[7] H. W. Parker, "Demand, Supply Will Determine When Oil Output Peaks,” Oil and Gas Journal, Vol. 100, No. 8, 2002, pp. 40-48.

[8] P. R. A. Wells, "Oil supply challenges - 2: What Can OPEC Deliver?” Oil and Gas Journal, Vol. 103, No. 9, 2005, pp. 20-30.

[9] P. R. A. Wells, "Oil Supply Challenges-1: The Non-OPEC Decline,” Oil and Gas Journal, Vol. 103, No. 7, 2005, pp. 20-28.

[10] S. M. Al-Fattah and R. A. Startzman, "Forecasting World Natural Gas Supply,” Journal of Petroleum Technology, Vol. 52, No. 5, 2000, pp. 62-72.

[11] A. Imam, R. A. Startzman and M. A. Barrufet, "Multicyclic Hubbert Model Shows Global Conventional Gas Output Peaking in 2019,” Oil and Gas Journal, Vol. 102, No. 31, 2004, pp. 20-28.

[12] C. J. Campbell and J. H. Laherrere, "The End of Cheap Oil,” Scientific American, Vol. 278, No. 3, 1998, pp. 7883.

[13] M. Höök and K. Aleklett, "Historical Trends in American Coal Production and A Possible Future Outlook," International Journal of Coal Geology, Vol. 78, No. 3, 2009, pp. 201-216.

[14] W. Zittel and J. Schindler, "Crude Oil the Supply Outlook,” Technical Report EWG-Series No 3/2007, Energy Watch Group, 2007.

[15] E. Guseo, A. Dalla Valle and M. Guidolin, "World Oil Depletion Models: Price Effects Compared with Strategic or Technological Interventions,” Technology Forecasting \& Social Change, Vol. 74, 2007, pp. 452-469.

[16] P. Bauquis, "Reappraisal of Energy Supply-Demand in 2050 Shows Big Role for Fossil Fuels, Nuclear but Not for Non-Nuclear Renewables,” Oil and Gas Journal, Vol. 101, No. 7, 2003, pp. 20-29.

[17] C. J. Campbell and S. Heaps, "An Atlas of Oil and Gas Depletion,” 2nd Edition, Jeremy Mills Publishing Limited, Huddersfield, UK, 2009. 


\section{Appendix 1}

Proof that the derivatives, corresponding to annual production, of the Generalized Hubbert and Bass Models are equal.

The Generalized Bass model is able to account for disruptions by introducing an intervention function, $x(t)$, into the Bass model. Following the same analogy, the Generalized Hubbert Model is defined by introducing an intervention function, $x(t)$, into the Hubbert model, given by Equation (1), in the same way, i.e.:

$$
\frac{d Q(t)}{d t}=r Q(t)\left(1-\frac{Q(t)}{Q_{T}}\right) x(\tau)
$$

Upon integration it can be shown that:

$$
Q(t)=Q_{T}\left[\frac{1}{1+\exp \left(-r\left(\int_{0}^{t} x(\tau) d \tau-t_{p}\right)\right)}\right] \times\left[\frac{\left[\left(1+\exp \left(r t_{p}\right)\right)+\exp \left(-r\left(\int_{0}^{t} x(\tau) d \tau-t_{p}\right)\right)-\exp \left(-r\left(\int_{0}^{t} x(\tau) d \tau-t_{p}\right)\right)\right]}{\left(1+\exp \left(r t_{p}\right)\right)}\right]
$$

Equation (A4) can be rearranged to obtain:

$$
Q(t)=Q_{T}\left[\frac{1}{1+\exp \left(-r\left(\int_{0}^{t} x(\tau) d \tau-t_{p}\right)\right)}\right] \times\left[\frac{\left(\exp \left(r t_{p}\right)-\exp \left(-r\left(\int_{0}^{t} x(\tau) d \tau-t_{p}\right)\right)\right)+\left(1+\exp \left(-r\left(\int_{0}^{t} x(\tau) d \tau-t_{p}\right)\right)\right)}{1+\exp \left(r t_{p}\right)}\right]
$$

which in turn, can be simplified to become:

$$
Q(t)=Q_{T}\left[\frac{\exp \left(r t_{p}\right)-\exp \left(-r\left(\int_{0}^{t} x(\tau) d \tau-t_{p}\right)\right)}{\left(1+\exp \left(r t_{p}\right)\right)\left[1+\exp \left(-r\left(\int_{0}^{t} x(\tau) d \tau-t_{p}\right)\right)\right]}\right]+Q_{T}\left[\frac{1}{1+\exp \left(r t_{p}\right)}\right]
$$

To the first term on the rhs of Equation (A6), multiply top and bottom by exp(-rt $t_{p}$ ), then Equation (A6) becomes:

$$
Q(t)=Q_{T}\left[\frac{1}{1+\exp \left(r t_{p}\right)}\right]\left[\frac{1-\exp \left(-r \int_{0}^{t} x(\tau) d \tau\right)}{\exp \left(-r t_{p}\right)+\exp \left(-r \int_{0}^{t} x(\tau) d \tau\right)}\right]+Q_{T}\left[\frac{1}{1+\exp \left(r t_{p}\right)}\right]
$$

To the first term on the rhs of Equation (A7), multiply top and bottom by $r\left(1+\exp \left(-r t_{p}\right)\right)$, then Equation (A7) becomes:

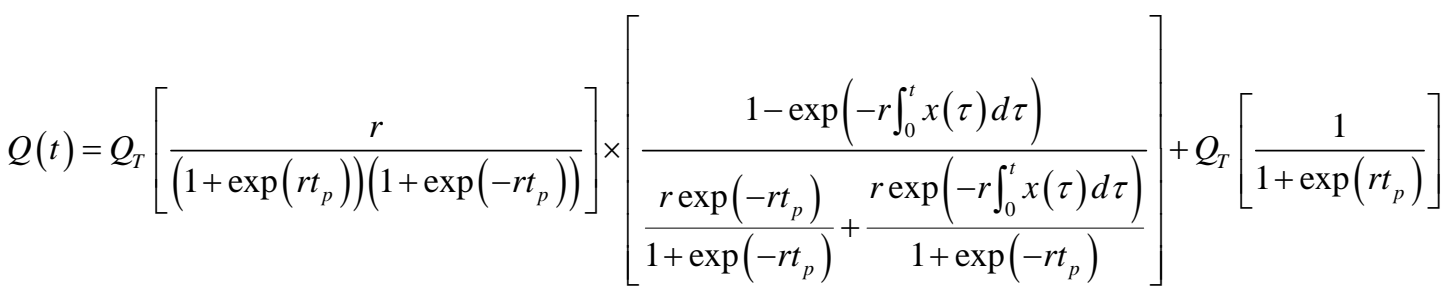

To the first term on the rhs of Equation (A8), multiply by 1 expressed in the form $\exp \left(r t_{p}\right) \exp \left(-r t_{p}\right)$, then Equa- tion (A8) becomes:

${ }^{3}$ Albeit a rather complicated expression for 1 . 


$$
\begin{aligned}
& Q(t)=Q_{T}\left[\frac{\exp \left(r t_{p}\right)}{1+\exp \left(r t_{p}\right)}\right]\left[\frac{r \exp \left(-r t_{p}\right)}{1+\exp \left(-r t_{p}\right)}\right] \times \\
& {\left[\begin{array}{r}
1-\exp \left(-\left[\left[\frac{r \exp \left(-r t_{p}\right)}{\exp \left(-r t_{p}\right)+1}\right]+\left[\frac{r}{\exp \left(-r t_{p}\right)+1}\right]\right] \int_{0}^{t} x(\tau) d \tau\right) \\
\left.\frac{r \exp \left(-r t_{p}\right)}{1+\exp \left(-r t_{p}\right)}+\frac{r}{1+\exp \left(-r t_{p}\right)} \exp \left(-\left[\left[\frac{r \exp \left(-r t_{p}\right)}{\exp \left(-r t_{p}\right)+1}\right]+\left[\frac{r}{\exp \left(-r t_{p}\right)+1}\right]\right] \int_{0}^{t} x(\tau) d \tau\right)\right]
\end{array}\right] Q_{T}\left[\frac{1}{1+\exp \left(r t_{p}\right)}\right]}
\end{aligned}
$$

The first term on the rhs of Equation (A9) is the Generalised Bass model as expressed in Equation (5). This can be demonstrated explicitly, by allowing:

$$
\begin{aligned}
& \hat{Q}_{T}=\frac{Q_{T} \exp \left(r t_{p}\right)}{1+\exp \left(r t_{p}\right)}, \\
& r_{1}=r \frac{\exp \left(-r t_{p}\right)}{\exp \left(-r t_{p}\right)+1}, \\
& r_{2}=r \frac{1}{\exp \left(-r t_{p}\right)+1} .
\end{aligned}
$$

Substiuting Equation (A10-12) into Equation (A9), produces:

$$
\begin{aligned}
Q(t) & =\hat{Q}_{T} r_{1}\left[\frac{1-\exp \left(-\left[r_{1}+r_{2}\right] \int_{0}^{t} x(\tau) d \tau\right)}{r_{1}+r_{2} \exp \left(-\left[r_{1}+r_{2}\right] \int_{0}^{t} x(\tau) d \tau\right)}\right] \\
& +Q_{T}\left[\frac{1}{1+\exp \left(r t_{p}\right)}\right]
\end{aligned}
$$

Now, the second term on the rhs of Equation (A13) is the constant ${ }^{4} Q(0)$, hence Equation (A13) can be rewritten as:

$$
Q(t)=\hat{Q}_{T}\left[\frac{1-\exp \left(-\left[r_{1}+r_{2}\right] \int_{0}^{t} x(\tau) d \tau\right)}{r_{1}+r_{2} \exp \left(-\left[r_{1}+r_{2}\right] \int_{0}^{t} x(\tau) d \tau\right)}\right]+Q(0) .
$$

Finally, substitute Equation (5) into Equation (A14) to obtain:

$$
Q(t)=\hat{Q}(t)+Q(0) .
$$

Since $Q(0)$ is a constant, differentiating Equation (A15), leads to:

$$
\frac{d Q(t)}{d t}=\frac{d \hat{Q}(t)}{d t}
$$

which shows that the annual production for the General-

${ }^{4}$ To see this substitute $\mathrm{t}=0$ into Equation (A2). ized Hubbert and Bass Models are equal, when the relationships, given by Equations (A10-12), are applied and that the cumulative production curves of the Generalized Hubbert and Bass Models, differ by the constant $Q(0)$.

Note: The Equations (A10-12) can be rearranged to obtain:

$$
\begin{gathered}
r=r_{1}+r_{2} \\
t_{p}=\frac{\ln \left(r_{2} / r_{1}\right)}{r_{1}+r_{2}}
\end{gathered}
$$

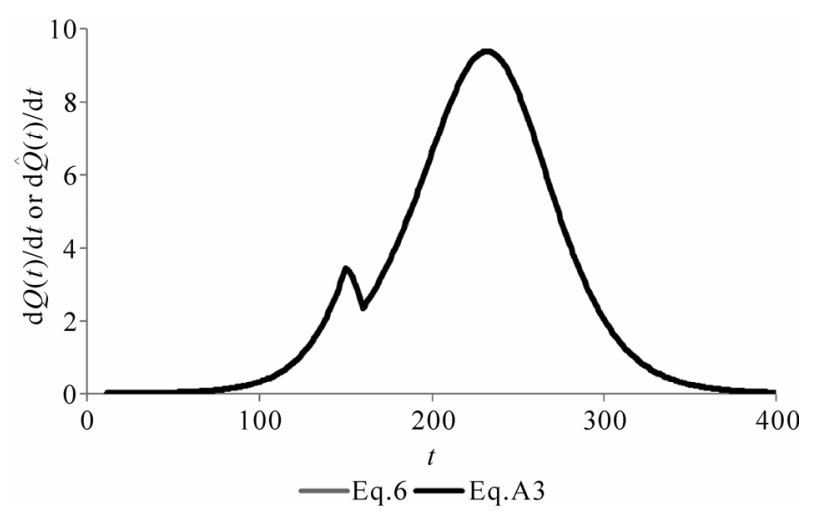

(a)

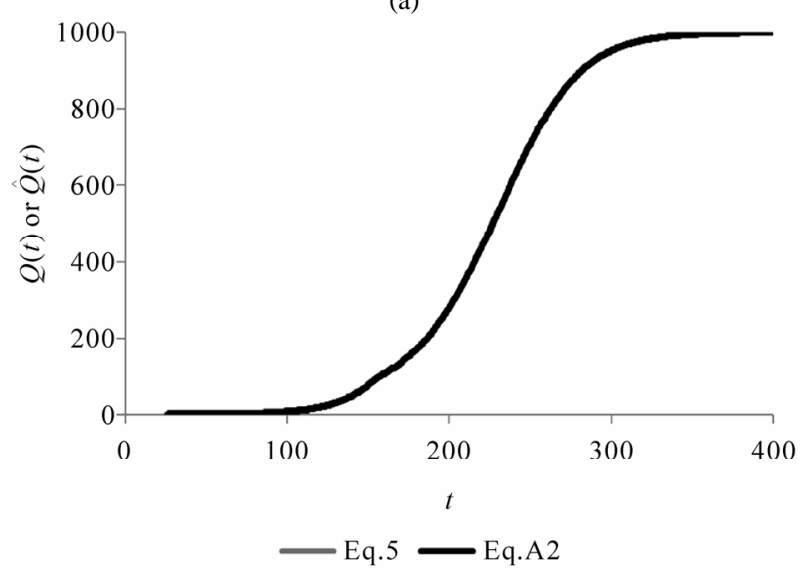

(b)

Figure A1. Comparison between Generalized Bass and Hubbert models. (a) Annual production; (b) Cumulative production. 


$$
Q_{T}=\hat{Q}_{T} \frac{r_{1}+r_{2}}{r_{2}}
$$

The following example is given to demonstrate that the Generalized Hubbert and Bass models provide equivalent predictions. Arbitrarily let $r=0.05 \mathrm{y}^{-1}, t_{P}=$ $200 \mathrm{y}$ and $Q_{T}=1000 \mathrm{~Gb}$, then from Equations (A10-12), $r_{1}=2.27 \times 10^{-6} \mathrm{y}^{-1}, r_{2}=0.05 \mathrm{y}^{-1}$ and $\hat{Q}_{T}=999.95 \mathrm{~Gb}$.
Suppose there is one disruption in year 150, and that $t_{r}=$ $10 \mathrm{y}, c=-0.5$ and $b=-0.01 \mathrm{y}^{-1}$. The plots of annual and cumulative production for both the Generalized Hubbert and Bass models are shown in Figure A1. It can be seen that annual production is identical, while the cumulative production is different only by a constant value of $\mathrm{Q}(0)=$ $0.05 \mathrm{~Gb}$. 